\title{
Accelerated evaluation of corrosion inhibition by means of the integral corrosion test
}

\author{
C. Andrade \& N. Rebolledo \\ Center for Safety and Durability of Structures and Materials (CISDEM-CSIC-UPM), Madrid, Spain
}

\begin{abstract}
Corrosion inhibitors, either added in the concrete mix or applied in corroding structures, are used to avoid or decrease reinforcement corrosion. Their efficiency is usually noticed by measuring the corrosion rate in several exposure conditions to detect the possible decrease of the corrosion rate or a repassivation. In present paper is presented the use of the named "integral corrosion test" to evaluate the inhibitor efficiency. This test consists in a migration test in which the cubic specimen has a bar embedded in its centre which starts to corrode when the chloride front arrives to it. It is called "integral" because it enables the consecutive detection of the diffusion coefficient, the chloride threshold and the corrosion rate. The diffusion coefficient is measured from the time taken until the steel bar starts to corrode, the chloride threshold by analysing a small sample of the steel/concrete interface just after depassivation and the corrosion rate, by measuring it in a twin specimen after the disconnection of the external voltage. The results indicate that the presence of inhibitors delay the depassivation time and decrease the corrosion rate developed while the chloride threshold appears to be higher. Then the test seems a good accelerated mode of studying inhibitor efficiency and can be also used to classify concrete resistance to chlorides.
\end{abstract}

\section{INTRODUCTION}

Corrosion of concrete reinforcements may be developed due to the chloride ingress in concrete or by the carbonation of the cover. The use of inhibitors are among the different preventive measures to delay the corrosion initiation (Page et al. 2000). These inhibitors can be added in the concrete mix or applied on the concrete surface although the reliability this last method is very controversial (Jamil et al. 2005). The efficiency of the inhibitors and their long term performance is still a subject of discussion as the data are scarce (Berke et al. 1993; Andrade et al. 1992) and not always conclusive (Kern et al. 2001; Loulizi et al. 2000).

One reason of the discrepancies is due to the testing method. They can be accelerated or in natural conditions. If they are accelerated (potentiodynamic or potentiostatic polarization curves) the problem lies in the extrapolation of the results to the real conditions at long term and if the methods are used for natural conditions (Polarization Resistance or corrosion potential measurements) then the doubts arrive due to the relative short term performance and questions arise on leaching of the inhibitor along time or their stability as chemical substance if the concrete is carbonated (Andrade, 1992).

In present paper a new method to evaluate in an accelerated manner the inhibition efficiency.
It is based in the principles of migration by accelerating the chloride penetration applying an external electrical field and measuring the time to depassivation. This method has been called "integral" corrosion test because it informs not only on the initiation but also on chloride threshold (Castellote et al. 2001) and on the reduction of the corrosion rate after depassivation, and is covered by the Spanish Standard UNE 83992-2 (Spanish Standard UNE 83992-2) "Durability of concrete. Tests of accelerated penetration of chlorides. Integral accelerated method". In present paper is illustrated its use to evaluate the corrosion inhibition by using the concept of "fictitious" diffusion coefficient as the chloride lasts longer to induce depassivation due to the presence of the inhibitor.

\section{METHODOLOGY}

\subsection{Inhibitors used}

In the Spanish Code (EHE-08) is accepted the use of preventive measures as inhibitors, for the lengthening of the service life and then, several inhibitors have been tested in our laboratory through this methodology in order to rank them with respect to the corrosion onset. For the sake of illustration, in present paper the known case of the addition of sodium nitrite is presented. Thus, $0,1.5,2$ y $2.5 \%$ 
of $\mathrm{NO}_{2}^{-}$by cement weight were added to the mix as indicated by the inhibitor manufacturer.

\subsection{Concrete materials}

The cement can be of any class depending of the particular application of the results although in present case an Ordinary Portland Cement was used. Two types of concrete of $50 \mathrm{MPa}$ of characteristic strength were fabricated as indicated in table 1.

\subsection{Procedures}

The specimens suggested are of concrete and of prismatic shape and the recommended size is of $10 \mathrm{~mm}$ or $15 \mathrm{~mm}$ although also of $7 \mathrm{~mm}$ are appropriate. The arrangement is shown in figure 1 .

The samples have embedded a corrugated bar of 8 or $10 \mathrm{~mm}$ in diameter at a distance reproducing the cover depth (around $3 \mathrm{~cm}$ in figure 1). The bar was cleaned from any rust prior to be embedded. The bar was isolated from the air/mortar interface by means of an insulating tape which also was used to protect the bar extreme inside the mortar.

A pond was glued to the surface of one of the faces of the specimen as shown in figure 1. A $1.2 \mathrm{M}$ $\mathrm{NaCl}$ solution was used to fill the pond: It is concentrated enough but not in excess, in order to not exhaust the chlorides during the testing.

A potential drop of 12 to $30 \mathrm{~V}$ is applied by means of a potential source through electrodes placed inside the pond (the cathode) and at the opposite face through a sponge (the anode). In order to detect the onset of corrosion, periodically the corrosion potential of the bar by means of a volmeter is measured by first switching off the potential drop during 30 to 180 minutes. The depassivation can be also detected by measuring the Polarization Resistance through a potentiostat. The $\mathrm{Rp}$ was measured by a sweep rate of $10 \mathrm{mV} / \mathrm{min}$ (Andrade et al. 1978). A constant B of $26 \mathrm{mV}$ was used for the calculation

Table 1. Concretes tested and amount of inhibitor added.

\begin{tabular}{llll}
\hline $\begin{array}{l}\text { Concrete } \\
\begin{array}{l}\text { Denomi- } \\
\text { nation }\end{array}\end{array}$ & $\begin{array}{l}\text { Type of } \\
\text { concrete }\end{array}$ & $\begin{array}{l}\text { Quantity of } \\
\text { admixture added } \\
\text { to the mix (kg) }\end{array}$ & $\begin{array}{l}\text { Quantity of } \\
\text { equivalent } \\
\mathrm{NO}_{2}^{-}\end{array}$ \\
\hline A_0 & & - & 0 \\
A_1.5 & HAC-50 & 30,7 & 1,5 \\
A_2 & 41,0 & 2,0 \\
A_2.5 & & 51,2 & 2,5 \\
\hline B_0 & & - & 0 \\
B_1.5 & HA-50/F50 & 30,7 & 1,5 \\
B_2 & & 41,0 & 2,0 \\
B_2.5 & & 51,2 & 2,5 \\
\hline
\end{tabular}

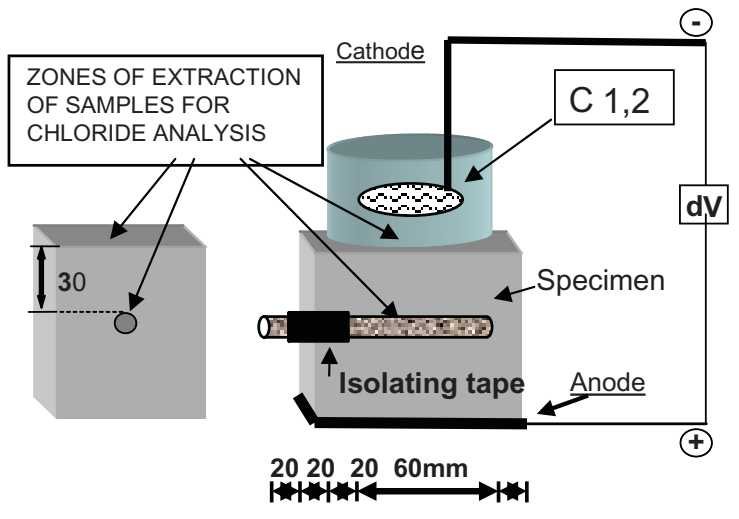

Figure 1. Accelerated chloride migration test setup.

of the corrosion rate, $\mathrm{I}_{\text {corr }}$ of the bar during the experiment. The depassivation is detected when the potential shifts below around $-350_{\mathrm{SCE}}$ or the $\mathrm{I}_{\text {corr }}$ is higher than $0.2 \mu \mathrm{A} / \mathrm{cm}^{2}$.

After depassivation is noticed, the specimen is broken in order to find out the chloride threshold. For it a small sample (about 2 g) near the bar over the corroded zone is extracted by means of a sharp pointed tool and a hammer. The chloride concentration values are given by concrete mass. In order to measure the corrosion rate after depassivation, other specimen is left to corrode naturally by switching off the potential applied during around 15 to 30 days. If the $I_{\text {corr }}$ in very corroded conditions is of interest, then the potential can be left applied until the bar is supposed very corroded and the Polarization Resistance is measured.

\subsection{Calculation of the non stationary Diffusion Coefficient, Dns.}

The non stationary Diffusion Coefficient is calculated by means of the following expressions (Castellote, 2001):

$$
D_{n s}=\frac{e^{2}}{2 \cdot t_{\text {lag }} \cdot \varphi} \quad\left[\mathrm{cm}^{2} / \mathrm{s}\right]
$$

where:

$$
\begin{gathered}
\mathrm{D}_{\mathrm{ns}}=\begin{array}{c}
\text { natural Non stationary diffusion coeffi- } \\
\text { cient }\left(\mathrm{cm}^{2} / \mathrm{s}\right)
\end{array} \\
\mathrm{t}_{\text {lag }}=\text { "time lag" or time until depassivation is } \\
\text { noticed }(\mathrm{s}) \\
e=\text { cover thickness }(\mathrm{cm}) \\
\varphi=\frac{z \cdot F}{R \cdot T} \cdot \Delta \phi=40 \text { for } 22^{\circ} \mathrm{C}=\text { to acceleration } \\
\text { factor of the electrical field. } \\
\Delta \phi=\frac{\Delta V}{L}=\text { normalized electrical field }(\mathrm{V})
\end{gathered}
$$


$\mathrm{L}=$ distance between electrodes (speimen thickness) $(\mathrm{cm})$

$\Delta \mathrm{V}=$ potential voltage drop applied(V)

$\mathrm{R}=$ Gas Constant

$\mathrm{F}=$ Faraday Constant

$\mathrm{T}=$ temperature $\left({ }^{\circ} \mathrm{K}\right)$

$\mathrm{z}=$ ion valence which is 1 for the chloride

\subsection{Calculation of Corrosion rate and Accumulated corrosion}

The accumulated corrosion $\mathrm{P}_{\text {corr }}$ is calculated from the Corrosion rate $\mathrm{I}_{\text {corr }}$ through:

$\mathrm{P}_{\text {corr }}=$ corrosion penetration $(\mathrm{mm})=0.0116 \times \mathrm{I}_{\text {corr }}$ $\left(\mu \mathrm{A} / \mathrm{cm}^{2}\right) \times \mathrm{t}$ (years)

$\mathrm{P}_{\text {corr }}$ can be also obtained from the integration of the $\mathrm{I}_{\text {corr }}$-time plot

\section{RESULTS}

\subsection{Results of the $E_{\text {corr }}$ and $I_{\text {corr }}$}

Figures 2 and 3 show the results of Corrosion potential along the experiment while figures 4 and 5 give the results of the corrosion rate registered in each concrete type. Either the $\mathrm{E}_{\text {corr }}$ or the $\mathrm{I}_{\text {corr }}$ indicate fairly well the depassivation onset. At the beginning the potential is noble but at certain time the potential drops indicating the starting of the corrosion.

With respect to the Corrosion rate, it is lower than $0.1 \mu \mathrm{A} / \mathrm{cm}^{2}$ at the beginning of the experiment to increase above $0.2 \mu \mathrm{A} / \mathrm{cm}^{2}$ simultaneously when the potential shifts.

The delay noticed in this shifting is proportional to the amount of Nitrites added. With respect to the inhibitor efficiency it seems that only the 2 and $2.5 \%$ proportions are almost fully effective by showing $I_{\text {corr }}$ values around $0.2 \mu \mathrm{A} / \mathrm{cm}^{2}$.

Figure 6 gives the critical chloride content measured in samples removed from the steel/concrete

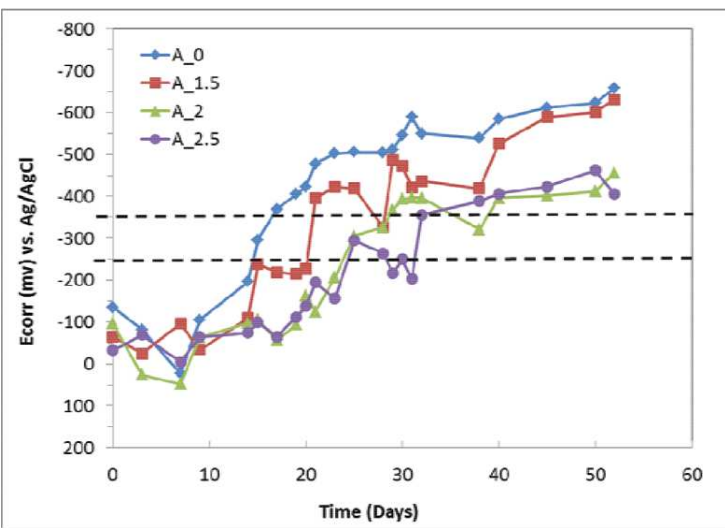

Figure 2. $\mathrm{E}_{\text {corr }}$ during time for concrete HAC-50.

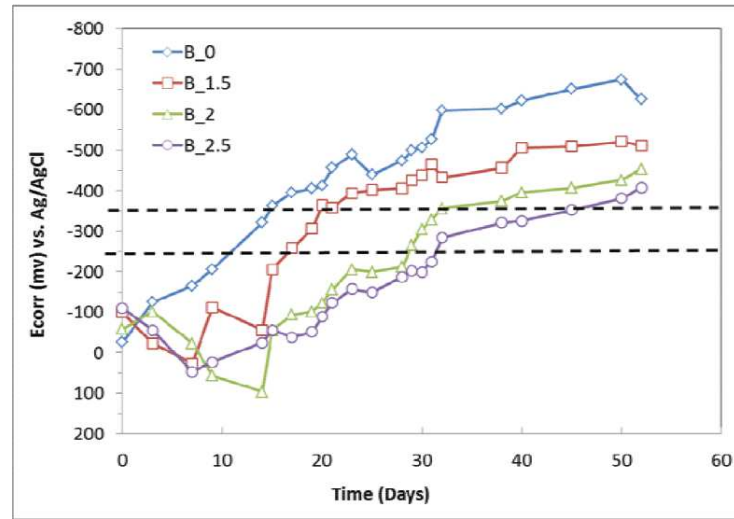

Figure 3. $\mathrm{E}_{\text {corr }}$ during time for concrete HA-50/F50.

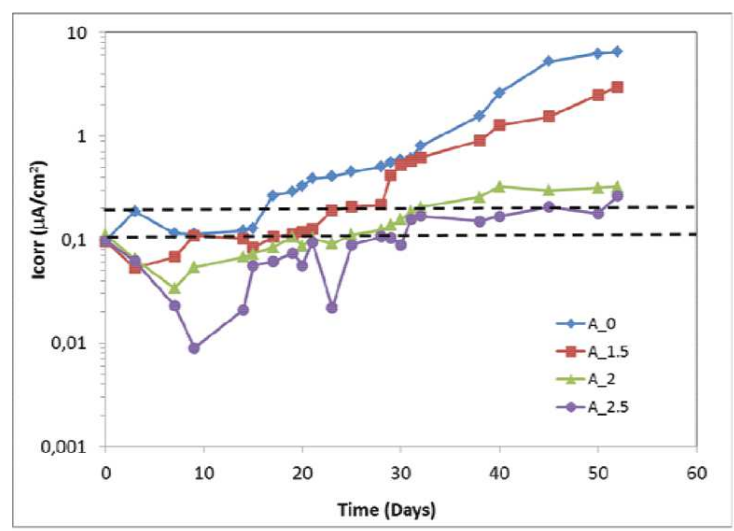

Figure 4. $\mathrm{I}_{\text {corr }}$ during time for concrete HAC-50.

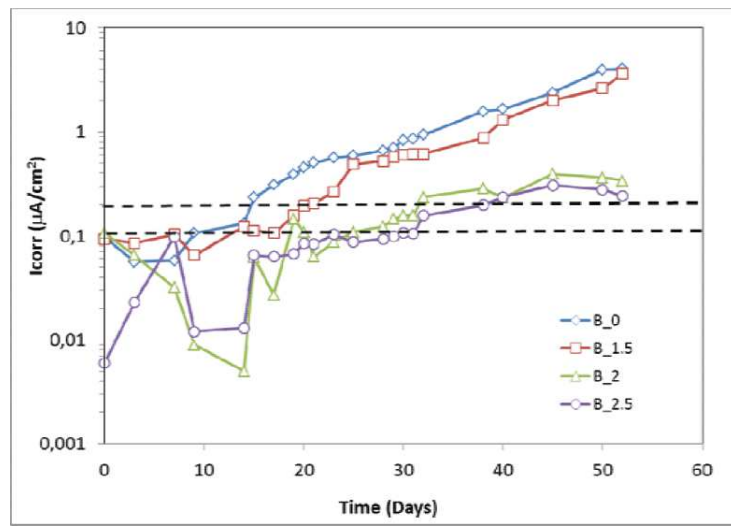

Figure 5. $\mathrm{I}_{\text {corr }}$ during time for concrete HA-50/F50.

interface after depassivation is noticed. The inhibition effect is also shown by the increasing chloride thresholds, Clth, that are registered when the nitrites added increase.

Regarding the Corrosion rates registered the values were low at the depassivation time but they 


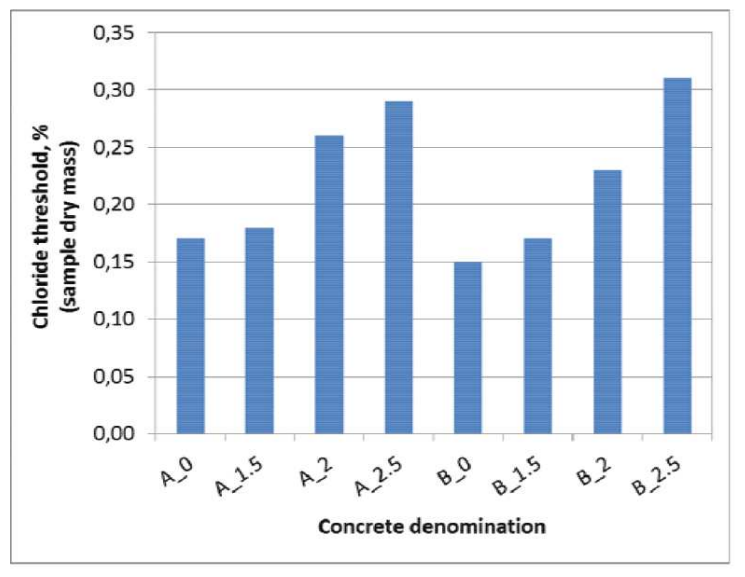

Figure 6. Critical chloride contents in the steel/concrete interface of the specimens after depassivation.

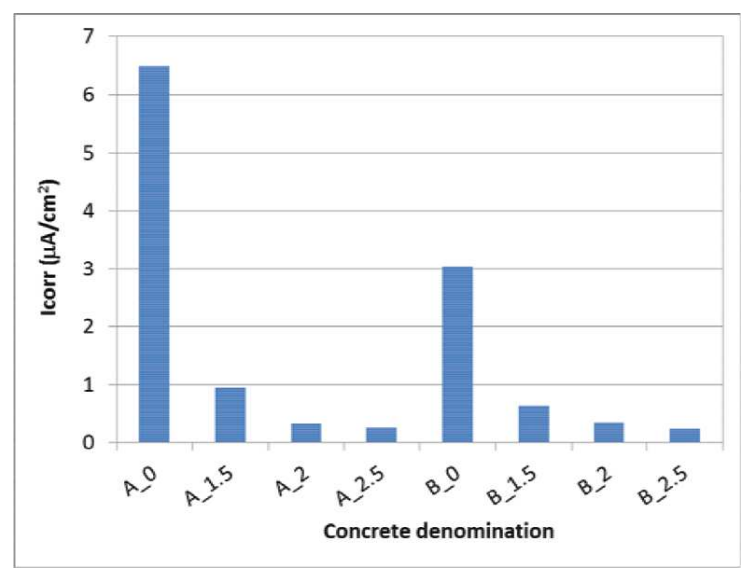

Figure 7. $I_{\text {corr }}$ values after 50 days of corrosion propagation.

increase with the chloride arrival and figure 7 gives the values found after 50 days of free corrosion.

\section{DISCUSSION}

The test has enabled the quick comparison of the service life parameters of the different amounts of inhibitors added because the testing times have been not longer than around one month. Actually, other inhibitors may give longer times to depassivation but it is not recommended that the test last more than 2 months because the hydroxide and protons generated at the electrodes due to the water electrolysis may influence the chloride threshold.

The diffusion coefficients calculated through the equation given in the experimental part are shown in figure 8. It has to be remarked that the lower $\mathrm{D}_{\mathrm{ns}}$ values found when the inhibitor is present has to be understood as a "fictitious" value in the sense that the concrete is almost the same (except small changes in the reology due to the presence of the inhibitor) and then the $\mathrm{D}_{\mathrm{ns}}$ should have been the same. They are different due to the longer times taken for the depassivation. In spite they are "fictitious" values however, they serve for the practical calculation of the corrosion initiation period.

\subsection{Inhibitor efficiency}

Regarding the inhibitor efficiency, it can be quantified through the calculation of the percentage of inhibition as indicated in the following expression:

$\%$ protection $=\frac{I_{\text {corr }}^{\text {without Inhibitor }}-I_{\text {corr }}^{\text {without Inhibitor }}}{I_{\text {corr }}^{\text {without Inhibidor }}}$

The values taken for this calculation are those given in figure 7. The results are shown in figure 9 which enables to deduce that the percentages of 2 and $2.5 \%$ give similar efficiencies.

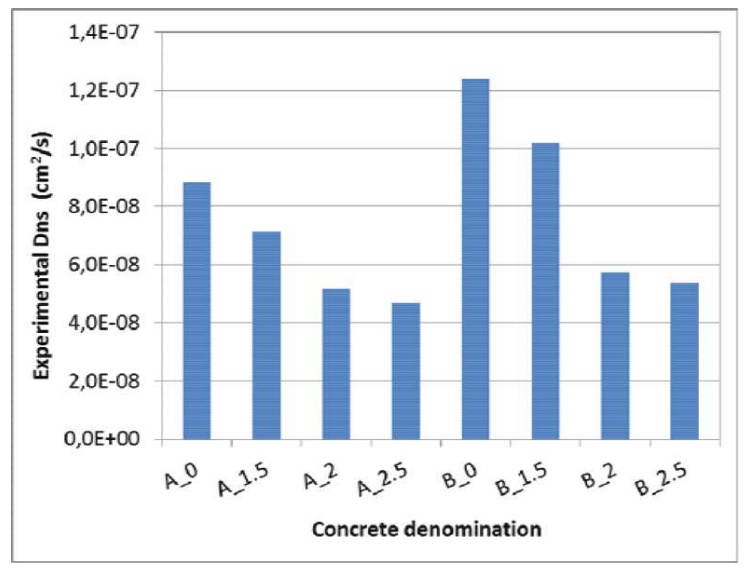

Figure 8. Diffusion coefficients calculated from the time to depassivation.

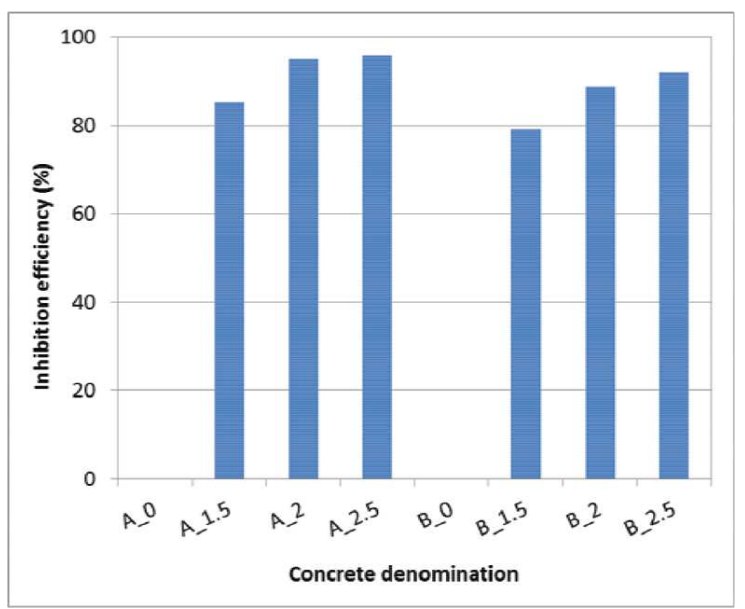

Figure 9. Calculated values of the percentage of inhibition. 
A final remark to be mentioned after the analysis of the results is that it seems that the applied voltage is not influencing the comparison. That is the electrical field, whatever is the voltage applied between 12 and 60 volts seems no influencing the registration neither the depassivation nor the chloride threshold value. Then, the method can be suggested as very practical for the evaluation of the inhibition efficiency due to its accelerated character.

\section{CONCLUSIONS}

The integral corrosion test standardized in Spain consists in accelerating the penetration of chloride ingress by means of applying an electrical field in a similar manner of the "rapid chloride permeability test" but it uses a steel bar to detect through the corrosion development, the arrival of the critical chloride front. The use of a steel bar seems to us a more suitable manner to account for the reinforcement depassivation than the simple measuring of the chloride concentration. The possibility to let the bar to corrode after corrosion starts gives the integral information for the service life prediction.

The test seems suitable not only for the calculation of service life parameters in the case of different concretes, but also it serves for the comparison of the inhibitor efficiency. In the cases tested no deleterious influence of the electrical field applied has been noticed.

For the sake of the inhibitor tested, it seems to delay the corrosion onset in both types of concrete proportionally to the increasing amounts added and to permit smaller corrosion rates after depassivation also following increasing owing inhibitor concentration.

\section{ACKNOWLEDGMENTS}

This work has been financed by the Spanish MICINN: INGENIO 2010-CONSOLIDER Project on "Safety and Durability of Structures: SEDUREC".

\section{REFERENCES}

Andrade, C. \& Gonzalez, J.A. 1978. Quantitative measurements of corrosion rate of reinforcing steels embedded in concrete using polarization resistance measurements, Werkstoffe und Korrosion 29: 515.

Andrade, C., Alonso, C., Acha, M. \& Malric, B. 1992. Preliminary testing of $\mathrm{Na} 2 \mathrm{PO} 3 \mathrm{~F}$ as a curative inhibitor for steel reinforcement in concrete. Cement and Concrete Research 22: 869-81.

Berke, N.S., Hicks, M.C. \& Tourney, P.G.1993. Evaluation of concrete corrosion inhibitors. In: Proceedings of the 12th international corrosion congress (ICC). Houston, Texas, USA: 74-8.

Castellote, M., Andrade, C. \& Alonso, C. 2001. Measurement of the steady and non-steady-state chloride diffusion coefficients in a migration test by means of monitoring the conductivity in the anolyte chamber. Comparison with natural diffusion tests. Cement and Concrete Research, 31: 1411-1420.

EHE-08 - Spanish Code for the calculation of structural concrete.

Jamil, H.E., Shrir,i A., Boulif, R. \& Montemor, M.F. 2005. Ferreire MGS. Corrosion behaviour of reinforcing steel exposed to an amino alcohol based corrosion inhibitor. Cem Concr Com, 27(6): 671-8.

Kern, P. \& Landolt, D. 2001. Adsorption of organic corrosion inhibitors on iron in the active and passive state. A replacement reaction between inhibitor and water studied with the rotating quartz crystal microbalance. Electrochim Acta 47: 589-98.

Loulizi, A \& Al-Qadi, I.L. 2000. Diefenderfer BK. Effects of nitrite-based corrosion inhibitor on concretes rapid chloride permeability values and its dielectric properties. ACI Mater J 97(4): 465-71.

Page, C., Ngala, V.T. \& Page, M.M. 2000. Corrosion inhibitors in concrete repair systems. Mag Concr Res 52(1): $25-37$

Page, C.L. 2000. Aspects of the performance of corrosion inhibitors applied to reinforced concrete. In: Proceedings of the ninth european symposium on corrosion inhibitors. Italy: University of Ferrara.

Spanish Standard UNE 83992-2 "Durability of concrete. Tests of accelerated penetration of chlorides. Integral accelerated method". 